\title{
Intervention Measures and Teaching Strategies Enhancing Mathematics Teaching to Dyscalculic Learners in Public Day Secondary Schools in Kericho County
}

\author{
Talam Josephine Chepkorir, Jessina Jessica Muthee \\ Department of Early childhood and special Needs Education, Kenyatta University, Kenya
}

\begin{abstract}
The purpose of this study was to investigate interventions measures and teaching strategies enhancing mathematics teaching to dyscalculic learners in public day secondary schools in Kericho county. Guided by Jean Piaget's theory of cognitive development, the study adopted a descriptive design which used mixed model research with both qualitative and quantitative approaches. The study was carried out in Kericho County. Semi-structured questionnaires were used to collect data for the study. The study was carried in 35 randomly selected public day secondary schools in different localities within the County to effectively analyze the methodologies of teaching the subject in the region. Data from the research instruments, namely mathematics teachers' questionnaires and mathematics students' questionnaires was coded and analyzed using the Statistical Package for Social Sciences (SPSS version 25) to obtain descriptive statistics. To ensure validity, face and content validity was conducted. Also, the Cronbach Coefficient Formula was applied to guarantee reliability. The findings revealed that 19 out of 300 randomly sampled students, which represent $6.3 \%$ of the total sampled students, suffered from dyscalculia. Also, reviewing the previous lessons and maximizing the use of homework were some of the major interventions that helped in enhancing dyscalculic learners' performance. The study recommends that the government should ensure a conducive classroom environment to enhance performance of dyscalculic students. It should also ensure that schools have enough teachers with special needs skills in all the schools.
\end{abstract}

Keywords: Dyscalculia: A mathematical learning disability which causes mild to severe problems in understanding, expressing, and computing mathematical concepts.

Teaching Strategy: A method employed by tutors to impart the desired instructional contents to learners in a holistic and effective manner

Improvement: State of being improved specially to enhanced value or excellence.

Intervention measure: Is a program or set of steps to help kids improve at things they struggle with. Instructional interventions focus on subjects like reading or math.

Special service: It's a form of learning provided to students with exceptional needs, such as students with learning disabilities

\section{INTRODUCTION}

$\mathrm{M}$ athematics study is recognized worldwide as the most important subject in most fields of human endeavors.
Its usefulness in science, technology, commerce, economics, education and even humanities is almost at par with the importance of education as a whole (Tella, 2017), it is also key in the understanding of other subjects such as chemistry, biology, and physics. This implies that for one to function well in the society and in this era of the technological age, he/she must possess relatively good mathematics knowledge. There exists an impregnable link between mathematics and other science subjects (Kiplagat, Role, \& Makewa, 2012). Learners' competency in numeracy and literacy in early grades affects their academic achievement more generally in later years and affects how they master other subjects (Wayne\& Youngs, 2003).

Dyscalculia is a condition that causes increased complexities for affected learners to grab basic mathematical concepts. Dyscalculic learners may have difficulty understanding simple number concepts, lack an intuitive grasp of numbers and have problems learning number facts and procedures. Even if they produce a correct answer or use a correct method, they may do so mechanically and without confidence. Dyscalculia and dyslexia can occur independently of each other or together. The strategies for dealing with dyscalculia will be fundamentally the same irrespective of whether or not the learner is also dyslexic (Landerl \& Butterworth, 2004). Thereare a number of factors which can affect the learning of mathematics (Meltzer, 2002). These may occur in isolation or may interact to create a potential learning difficulty. With appropriate help, most of the difficulties associated with these factors can be alleviated or circumvented.

In Kericho County, students affected with dyscalculia and dyslexia are drawn from disparate socio-economic backgrounds. The students were identified based on their individual performance in the subject of mathematics as well as the input of teachers regarding their overall subject performance. In this case, continuous assessment tests play a pivotal role in identifying a student's aptitude towards solving mathematical problems. Sustained and severely low performance on mathematics tests by some students in the County points to the prevalence of learning difficulties. 
One of the sources of mathematics difficulty may be as a result of teaching strategy applied to each learner. According to Onwumere (2009), every learner is unique and learns in a particular approach. Onwumere stated that any teaching which does not take into account learners limiting factors rarely succeeds. The researcher further noted that teachers who realize the learning needs of their pupils are more empowered to provide the kinds of instructions their learners need. Identifying the root cause of a pupil's struggle to learn, provides a starting point for understanding why a particular strategy is efficient for the learner (Onwumere, 2009). Mathematics difficulty might be as a result of developmental dyscalculia which is a specific learning disability affecting the usual acquisition of mathematics skills (Shalev, 2004).

According to Martin (2000), learners who do not get their educational needs met in mathematics, not only fail to perform well academically but also fail to trust their own mathematical sense. Prevatt, Welles, Li, \& Proctor (2010)posit that when these students are faced with any element of mathematics, significant anxiety in their performance and behaviour is noted. In most African nations, very little is known about dyscalculia. Learners with dyscalculia are quite often referred to as low achievers, slow learners or lazy by teachers and parents (Nyaga, 2012). The teachers normally ignore them and concentrate on those who do not experience such disabilities. Poor performance in mathematics has continued to be witnessed despite various government initiatives put in place. For instance, the Government of Kenya with the help of JICA introduced a project called SMASSE (Strengthening Mathematics and Science) in primary schools in 2006 (Mutambuki, 2014).

Although the prevalence of reading problems on the one hand and mathematics learning problems on the other hand seems to be equal (Kenney, Hancewicz, Heuer, Metsisto \& Tuttle, 2005), this is not reflected in the amount of research focusing on each field (Saxe, 2015). Far more research is carried out in the field of reading, while the field of mathematics remains underdeveloped. The present study tackles this shortcoming by focusing on mathematics learning difficulties (dyscalculia). Moreover, taking into account research indicating that especially early interventions are effective, we focus on mathematics learning difficulties in secondary education.

The aim of the current study is two-fold. First, on the basis of teachers' pedagogical content knowledge, an effort is made to develop an overview of mathematics learning difficulties in secondary education. Second, an attempt is made to analyze the implementation of a specific available teaching strategies which are used to assist students with learning difficulties.

\subsection{Statement of the problem}

Mathematics performance in Kericho County has been on the decline in the last five years. That is between 2013 to 2017. Data from the six sub counties indicate that the highest mean was 3.36 while the lowest mean was 2.77 . This means majority students failed to qualify to proceed for further education to pursue mathematics and science-oriented courses such as medicine, engineering and technological courses. This becomes a problem to the society in that a good percentage of the population may become unemployed and dependent. In an ideal situation student should proceed to TVET or Universities to study and become either employed or self-employed. Poor performance in mathematics could be associated with many problems including having many students with dyscalculia. Research findings from this study may be used to help improve mathematics performance since appropriate strategies will be recommended. Further challenges faced by tutors would be addressed leading to better performance. The government too may use findings to make appropriate policies for purposes of intervention.

\subsection{Purpose of the study}

The purpose of this study was to investigate intervention measures and teaching strategies enhancing mathematics teaching to dyscalculic learners in public day secondary schools in Kericho County.

\subsection{Research Question}

What are the possible intervention measures and teaching strategies that can be undertaken to improve the teaching of mathematics to learners with dyscalculia in in public day secondary schools in Kericho County?

\subsection{Theoretical framework of the study}

This study was guided by the Jean Piaget theory of cognitive development, which enhances an understanding of learning dyscalculia(Shalev, 2003). According to this theory, the maturation of cognitive skills, or thinking, follows a sequential progression. An individual child's ability to learn depends on his/her current nutritional status. Any attempts to speed up or bypass the developmental process may create problems (Charlesworth, 2017). Cognitive development refers to the changes that occur in an individual's cognitive structures, abilities, and processes.

According to Driscoll (2013), cognitive development is the transformation of the child's undifferentiated, unspecialized cognitive abilities into the adult's conceptual competence and problem-solving skill. However, what exactly changes with development? Piaget believed children's schemes, or logical mental structures, change with age and are initially actionbased (sensorimotor) and later move to a mental (operational) level. Further, Piaget believed the cognitive performance in children is directly associated with the cognitive development stage they are in. Each individual has a pre-set rate of growth for various human functions including cognitive abilities. Discrepancies among the various abilities indicate that the abilities are maturing at different rates with some abilities lagging in their development. Most children with learning 
dyscalculia experience developmental delay and/or may fail to reach the higher stages and therefore do not accomplish relevant activities at the right time.

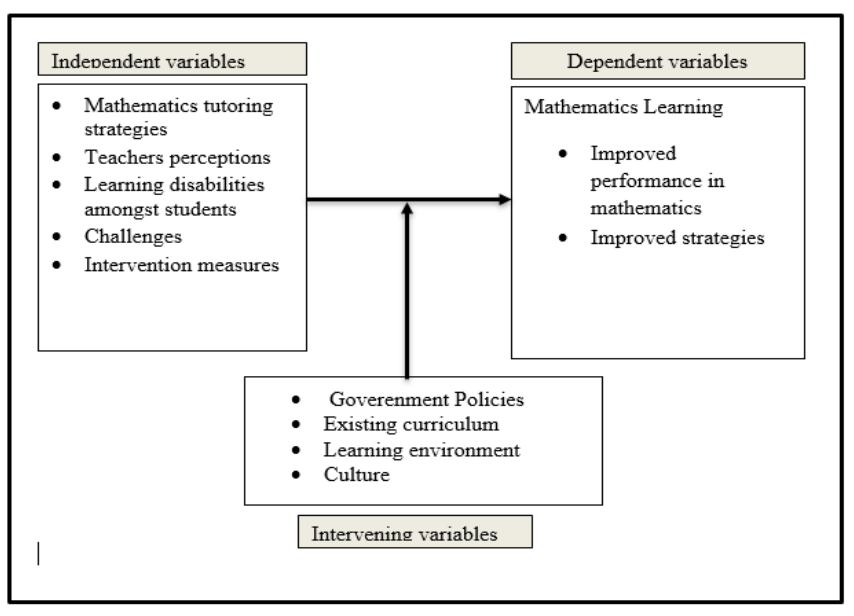

Figure 1: Conceptual Framework

\section{EMPIRICAL REVIEW}

Intervention measures and possible teaching strategies are complex processes and transverses individual parents, teachers and the society. Despite the continued expansion of Educational Assessment and Resource Centers (EARCS) to all Counties in Kenya since inception in September 1984, these centers are faced with a number of challenges. Most of the screening tools and equipment used in the EARCS are for children with Visual impairment, hearing impairment, mental handicap and Physical disabilities, which are inadequate, and need revision, updating and validation. There are no diagnostic tools for assessing specific cases such as learning difficulties, giftedness, talentedness and behavioral difficulties. Hence, most learners with special needs education end up being mislabeled and given wrong placement (Republic of Kenya, 2005). A study of Cost and Financing of Special Education in Kenya sponsored by the Ministry of Education and World bank (World Bank, 2004) found out that only 0.5 per cent of the estimated 2.3 million children with special needs aged 0 to 19 years were receiving special education services in primary, secondary, integrated schools and special units. However, programmes for children with dyscalculia did not exist in both primary and secondary schools. Hence there is a need for a study to investigate the methodologies of tutoring such learners. A number of factors account for this underdeveloped state of the country's special needs education. Prior to the formulation and effectuation of the policy framework for special needs education in 2010 , there was no policy or legal framework to guide special needs education in Kenya despite the various policy guidelines given by the various commissions and task forces (Kochung, 2011).

To close the legal framework gap, the Persons with Disabilities Act 2003 was introduced, however, it does not mention anything about assessment of special needs children.
Other challenges facing the government in providing special needs education include identifying and rehabilitating all those with special needs, increasing budgetary support for special education, training more teachers, providing more resources and initiating integration programmes for children with learning needs in regular schools (Elimu Yetu Coalition, 2003). As a result of the challenges facing special needs education, a lot remains to be done if children with all forms of special needs are to be catered for. Teachers still need practical skills to assess and manage dyscalculia.

It is in this light that Elsa Abreau, the Headmistress of Kestrel Manor School for dyscalculia, says the resources needed are not available and at the end of it all, the job of assisting these children translates into a calling, "Unfortunately, training of teachers in special needs education is more theoretical than practical and we are having situations where some of the teachers with special education training don't know what to do when they are finally sent out." Rasugu (2010) refers to dyscalculia as a complex emerging area probably because not much research has been undertaken in the area and recommends that the Kenya Institute of Curriculum Development (K.I.C.D.) develops guidelines for teachers to assist children with specific learning disabilities in regular classrooms, and the Kenya National Examinations Council (KNEC) take cognizance of these children and plan examination papers and schedules with these children in mind (Kenya Institute of Education, 2002).

As already noted, there are no special programmes specifically for dyscalculia like in other established special needs areas safe for a few units now coming up within regular schools. Therefore, within the larger framework, dyscalculia continues to be neglected, except for some sporadic work by a handful of concerned individuals. The exact number of LD cases in Kenya is not known. However, Fletcher, Coulter, Reschly, and Vaughn (2004) estimates the figure to be between 30 per cent and 40 per cent of schools going population. Without reliable data, there is no meaningful planning that can be done to cater for the affected children. Children with learning disabilities need to be identified in order to make adequate provisions for them. Having looked at the literature, this study will address the following; establishing the presence of dyscalculia, the nature and prevalence of dyscalculia, intervention measures in place and lessons to learn from developed countries.

According to Van Steenbrugge, Valcke, \& Desoete (2010) two types of learning problems can be distinguished: a learning disability is situated in the child's own cognitive development, whereas the cause of a learning difficulty is situated outside the child or in another problem in the child. In this study, we focus on mathematics learning difficulties. Or as post "Individuals who exhibit learning difficulties may not be intellectually impaired; rather, their learning problems may be the result of an inadequate design of instruction in curricular materials". 
In the literature, no concrete numbers are reported about the prevalence of mathematics learning difficulties. In contrast, the prevalence of mathematics learning disabilities is estimated at approximately five to eight percent (Karagiannakis, Baccaglini-Frank, \&Papadatos, 2014). Compared to the large number of studies focusing on student with learning disabilities, little systematic evidence-based approaches are available about learners with learning difficulties. The present study is presented as a concrete starting point to develop such a line of research.

Although research stresses that the diagnosis of a learning disability can only be drawn from a global assessment of the child including learning and the school context (Dyson, 2003), the diagnosis is principally based on a (combined) use of diagnostic tools Van Steenbrugge et al. (2010) while neglecting the knowledge and the experiences of the mathematics teacher. Therefore, in the present study, an effort is made especially on the teachers' knowledge of and experiences with mathematics learning difficulties.

Learning disabilities (LD) refer to a set of central nervous system disorders that affect an extensive range of academic and functional skills (Beauchemin, Hutchins, \& Patterson, 2009). According to Tuchura (2016), LD is a neurologically based disorder in which the nerve-cell connections fail to function properly. The learning disabilities occur due to the intended information not reaching a specific target in the brain. The condition leads to unanticipated under-achievement in learners whose intelligence is average or above average. Learning disability is one of the least understood and most disputed disabling condition that affects children. Kavale and Forness (2012), record that the field continues to be beset by persistent, and occasionally contentious disagreement about the definition of the disorder, diagnostic criteria practices, treatment procedures and education policies.

According to Sleeter (2010), America has made achievements in the field of learning disabilities (LD) in four major areas. First, more children are currently being served in LD programs than in any other area of special education. Secondly, labelling LD students as culturally deprived was dropped and thirdly, pressure for learners to achieve in specific tests was elevated. Finally, the degree of inclusion of LD students across all social stratification was increased significantly (Sleeter, 2010). Chow and Priebe (2013) observe that institutions for people with learning disabilities existed in the Netherlands at the end of the 19th century with large institutions being built after the 2nd World War. All people with learning disabilities get some care from care providers in institutions, in the community or in special schools where they have their daily care and activity in day care centers for children/adults.

The government and professional groups embrace four concepts in the process of care provision: the concept of Tailor-Made Care, the Quality of Care Act, the personal contract and the individual care plan along with the coordinating role of the case manager. Whereas Sweden has provided for pupils with dyscalculia since 1866 when the first special school was established for pupils with dyscalculia, the law for people with dyscalculia came into force in 1944, which provided for children and young people with mild dyscalculia. Another law followed it in 1954. With the inception of the Act concerning support and service for persons with certain fundamental impairment (Disability act) in 1994, local authorities have taken over responsibility for support and provision of services for persons with dyscalculia (Chow \& Priebe, 2013). However, it is significant to point out that what happens in developed countries is in sharp contrast to the situation obtaining in developing countries where learning disabilities is an emerging new area.

\section{Intervention Measures for Educational Purposes}

If learning disabilities are suspected, the teacher may refer students for special education assessment. Parents are notified of the reasons for referral and presented with an assessment plan prepared by the educational team. If consent is given for special education evaluation, the team begins to collect information about the student (Burrell, 2000). There are a number of intervention strategies for children with learning disabilities. However, it should be noted that there is no specific teaching method or technique, which can be used as a cure, thus teachers should apply a wide range of instructional materials and techniques (Eison, 2010). The following is an overview of the techniques that have been discussed by Narh (2017).

\section{Special Services}

When assessment is complete, the teacher, parent/guardian, local education authority (and the student, if possible), can plan the student's Individualized Educational Program (IEP). While the resource room is the most typical placement for learning disabled students, self-contained special classes are provided for those with comprehensive learning needs. Whereas some students with LD receive assistance in oral language development from speech-language clinicians' others receive counselling from the school counsellor, social worker or school psychologist.

\section{Task Analysis}

Task analysis involves breaking down a task into several components, which in turn are divided into sub-components. In teaching a task, which requires manual manipulation, a child observes how a model or master performer performs the task and tries to imitate (Grabe \& Stoller, 2013).

\section{Precision Teaching}

This technique uses a chart on which the teacher records the progress in the child's behavior in relation to the desired or target behavior. The graph is called The Class Behaviour Chart. The child's daily progress on a given task is recorded and also the rate of performance. 


\section{Behavior Modification}

This is an effective measure in remediating learning problems, eliminating undesirable behaviors and establishing desirable ones. In addition to these techniques that are to be used in class, there are other interventions, which can be administered outside the school, which are outlined below:

\section{Administration of Drugs}

Hyperactive children are constantly in motion, restless and impulsive. Physicians tend to treat these characteristics by prescribing drugs to calm them. Though some caution has to be taken in the treatment of hyperactivity, drugs have nonetheless been found to produce substantial academic and behavior improvements.

\section{Dietary Management}

Another controversial approach used in the treatment of hyperactivity is the management of diet (Arnold, Lofthouse, $\&$ Hurt, 2012). Some chemicals found in food, including additives and food coloring, cause children to become hyperactive. However, Narh (2017) cast some doubt that diet management can reduce hyperactivity in the child.

The literature reviewed confirms that the definition of learning disabilities is debatable. Despite this, there is evidence from the literature that learning disabilities indeed exist among learners who appear capable but experience extreme difficulty in some areas of learning such as orientation, reading, writing, spelling, comprehension, and arithmetic. Owing to controversies surrounding the definition, there is no known cause of learning disabilities. However, the literature outlines a number of possible causes, which include: educational factors, environmental factors, psychological factors, and physiological factors. Limited research has been conducted in other countries with the consequence that teachers may not be aware of the manifestations or the prevalence of learning disabilities.

Most of the research that has been conducted in Kenya is mainly on reading difficulties. This study was an attempt to fill the apparent research gap in Kenya by conducting a research study in schools located in Kericho county with an attempt to evaluate the nature of dyscalculia and to give possible interventions measures and teaching strategies that should be used to help in this problem. Literature has also shown that most common teaching strategies include task analyses, behavior modification, precision teaching, and dietary management.

\section{MATERIALS AND METHODS}

A descriptive survey research method was used in this study. The design allows description of variables, both dependent and independent under study without manipulation and gives the researcher an opportunity together, summarize, interpret and analyze the data collected. The target population in this study comprised of all secondary school students in Kericho County. However, the study specifically dealt with the accessible 117 public day secondary schools in Kericho County. In the accessible schools, there were two hundred and sixty-four (264) mathematics teachers and nine thousand six hundred and two $(9,602)$ students, of whom five thousand five hundred and thirty-five $(5,535)$ were boys and four thousand and sixty-seven (4067) were girls.

Stratified random sampling was used. In this kind of sampling a population is divided into subgroups called strata and a sample is selected from each stratum. In this case the strats were the subcounty. Schools were then picked in such a way that the sub counties were proportionally represented. Teachers were purposively selected from the sampled schools depending on whether they teach the selected class or not.

The sample size is determined by a prior calculation of the sample size required to meet specified confidence limits for the population values. According toGorard (2001) a sampling fraction of between 10-20\% of total population in descriptive research is acceptable. A total of thirty-five (35) secondary schools were selected from one hundred and seventeen (117) secondary schools in the County. Twenty-nine (29) mathematics teachers were selected for the study out of the 264 mathematics teachers in the county. This constituted approximately $11 \%$ of the total mathematics teachers' population. Similarly, three hundred (300) form three and four students, who had scored less than $25 \%$ marks in mathematics in the previous year, were selected from approximately two thousand six hundred and two $(2,602)$ of the student population from the thirty five selected schools.

Table 1: Sampling Size

\begin{tabular}{|c|c|c|c|}
\hline Category & Population & Sample & Percentage \\
\hline Schools & 117 & 35 & $30 \%$ \\
\hline $\begin{array}{c}\text { Mathematic } \\
\text { teachers }\end{array}$ & 264 & 29 & $11 \%$ \\
\hline Students & 2602 & 300 & $11 \%$ \\
\hline
\end{tabular}

The researcher conducted a pilot study in five secondary schools. The schools are located in the same county but was not included in the main study. A pilot study served to validate the survey items by crosschecking their reliability as well as other statistical procedures for analyzing data. Pilot study data was also used to test the instruments' validity. Qualitative data was obtained from the open-ended items in both the students and teacher questionnaires. The data were grouped into different categories/themes consistent with the research objectives and deduction and generalizations were made using patterns and trend of responses. Quantitative data was obtained from closed ended items in the student and teacher instruments. The data were entered on the spreadsheet and coded in the computer. SPSS v25 was used to analyze the data. Frequency tables and pie charts were used to summarize and report the findings. All data collected were kept confidential and anonymous. 


\section{RESULTS AND DISCUSSION}

4.1 Intervention Measures and Teaching Strategies to Improve the Teaching of Mathematics to Learners with Dyscalculia

\subsubsection{Intervention Measures}

This study sought to investigate possible intervention measures and teaching strategies enhancing mathematics teaching to dyscalculic learners in public day secondary schools in Kericho County. Teachers were also required to respond to the possible intervention measures that would help to improve dyscalculic learners' performance. The majority strongly agreed or disagreed on the measures that were proposed by the researcher.

Table 4.1: Results of the possible intervention measures

\begin{tabular}{|c|c|c|c|c|c|c|c|}
\hline Intervention Measures & 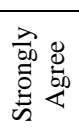 & 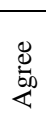 & 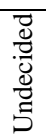 & $\begin{array}{l}\mathscr{D} \\
\stackrel{\mathscr{D}}{0} \\
\mathbb{D} \\
\stackrel{\mathscr{D}}{0}\end{array}$ & 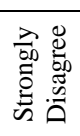 & $\stackrel{\Xi}{\Sigma}$ & $\begin{array}{l}\dot{\vec{\nu}} \\
\dot{\vec{\omega}}\end{array}$ \\
\hline $\begin{array}{l}\text { Use of ICT can help to improve performance of learners with } \\
\text { dyscalculia }\end{array}$ & 12 & 14 & 1 & 1 & 1 & 1.79 & 0.94 \\
\hline Use of learning areas with minimum distraction & 10 & 14 & 3 & 2 & 0 & 1.9 & 0.86 \\
\hline A classroom with relevant and recent displays & 6 & 13 & 3 & 2 & 5 & 2.55 & 1.38 \\
\hline $\begin{array}{l}\text { Reviewing the previous lessons to improve the performance of } \\
\text { students with dyscalculia }\end{array}$ & 15 & 9 & 3 & 1 & 1 & 1.76 & 1.02 \\
\hline $\begin{array}{l}\text { Homework and marking should be meant to improve learners } \\
\text { diagnosis of the weak areas }\end{array}$ & 5 & 18 & 3 & 3 & 0 & 2.14 & 0.83 \\
\hline $\begin{array}{l}\text { The lesson should be planned such that learners will be allowed to } \\
\text { verbalize their thinking }\end{array}$ & 6 & 7 & 3 & 11 & 2 & 2.86 & 1.33 \\
\hline $\begin{array}{l}\text { A conducive environment that increases interactivity among the } \\
\text { learners with dyscalculia and the well-performing learners during the } \\
\text { lesson }\end{array}$ & 12 & 10 & 4 & 2 & 1 & 1.97 & 1.09 \\
\hline
\end{tabular}

Table 4.1 indicates that, the majority $(90 \%)$ of the teachers were in agreement that the use of ICT could, in future, help to improve the performance of learners with dyscalculia $(\mathrm{M}=1.79, \mathrm{SD}=0.94)$. Use of digital dyscalculia screeners may be effective in enhancing a more ideal procedure in the disorder identification. Currently, most of the computer-based screeners are only available for students with 14 years and below (Drigas \& Pappas, 2015). Nevertheless, Beacham \& Trott (2005) developed DyscalculiUM, a computer-based screener that is able to mark the mathematical questions automatically during the screening test process and retain a record of individual scores for each of the tested high school and undergraduate learners. Such a program may be crucial in reducing errors associated with manual dyscalculia identification tests.

The $48 \%$ of the sampled teachers agreed that the use of learning spaces with minimum distraction would help to improve the performance of learners with dyscalculia $(M=1.9$, $S D=0.86$ ). For instance, some of the classrooms that could comfortably host about 50 students had more than 70 students. According to Udoba (2014), learners with learning disabilities such as dyscalculia need enough space to carry out several activities. In addition, other students lacked enough desks such that three students could share a desk. Some classrooms lacked ceiling boards, doors, and windows and as such, the learners were not shielded fully from the outside weather variations.

About $45 \%$ of the teachers agreed that a classroom with relevant and recent displays created an environment that could assist dyscalculic learners to improve their performance $(M=2.55, S D=1.38)$. In a mathematics class, learners should be surrounded by displays such as graphs to help them understand the grid lines and the axes. All the classes lacked these displays of which the dyscalculic learners could have the mathematical concepts in the displays sticking to their minds better. Generally, the majority of such displays are found in primary schools.

The majority (52\%) of the teachers strongly agreed that reviewing the previous lessons to improve the performance of students with dyscalculia was crucial to the improvement of dyscalculic learners' performance $(M=1.76, \quad S D=1.02)$. Furlong et al. (2016) noted that since dyscalculia is a mental disorder, revisiting the previous lessons was an important task to allow the dyscalculic learners to develop a better grasp of a mathematical concept. A special time should always be set to allow the teacher to engage the poorly performing learners on the previously taught items.

Nearly $62 \%$ of the teachers agreed that homework and marking should be meant to improve learners' diagnosis of the weak areas $(M=2.14, S D=0.83)$. Carr (2013) also reported that homework reinforces the knowledge that has been acquired in class when the learners are in non-institutional environments. The researcher proceeds to say that it is unfortunate that teachers do not utilize homework as a way to improve the learners' performance. A meta-analysis carried out by Cooper \& Schindler (2008) revealed that academic achievement has a strong positive correlation with the amount of homework given to students. Teachers in public day secondary schools in 
Kericho County are therefore in a good position to improve the performance of the dyscalculic learners through assigning homework to the learners.

Most (38\%) of the teachers disagreed that the lesson should be planned such that learners will be allowed to verbalize their thinking $(M=2.86, \quad S D=1.33)$. This is perhaps due to intimidation that the dyscalculic learners would go through whenever they are compelled to make their thinking be heard aloud. However, Hartman (2001) and Tobiason, Heritage, Chang, Jones, \& Herman (2014) believe that by allowing learners to verbalize their thinking, a substantive insight into learners' thinking development is revealed to the teachers. This is necessary for teachers in public day secondary schools in Kericho County to assist their students in changing their perspectives when tackling mathematical problems because they will not treat all the students' weaknesses in the same way.

About $41 \%$ of the sampled teachers strongly agreed that a conducive environment that increases interactivity among the learners with dyscalculia and the well-performing learners was necessary to address the issues of dyscalculia $(M=1.97$, $S D=1.09$ ). Sometimes mathematics teachers should dedicate some time to learners' interactions through discussions. The group discussions should engage both the poorly and the good-performing student categories to allow the interaction, which should be overseen by the teachers. This is in line with the findings of Smith et al (2009) and Sofroniou \& Poutos (2016) who explained that when learners are allowed to discuss during the mathematics class, they develop a problemsolving critical thinking while appreciating their colleagues' views on different mathematical problems.

\subsubsection{Teaching Strategies}

Teachers gave their opinions on the teaching strategies in which they felt could assist them to handle the dyscalculic learners. They seemed to either strongly agree or agree on most of the strategies that the researcher suggested. The results for this section are presented in Table 4.2.

Table 4.2: Results of the possible teaching strategies

\begin{tabular}{|c|c|c|c|c|c|c|c|}
\hline Strategies & 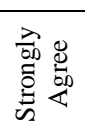 & 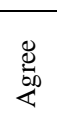 & 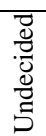 & 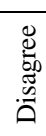 & 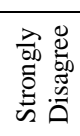 & 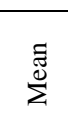 & $\begin{array}{l}\dot{\vec{\nu}} \\
\dot{D} \\
\dot{D}\end{array}$ \\
\hline $\begin{array}{l}\text { Relevant and familiar contexts should be linked to mathematics e.g. } \\
\text { football tables, indoor and outdoor resources }\end{array}$ & 10 & 8 & 5 & 5 & 1 & 2.28 & 1.22 \\
\hline $\begin{array}{l}\text { Moving to the higher level when a learner has understood the easier } \\
\text { contexts; it will thus require more time to do so }\end{array}$ & 10 & 13 & 3 & 2 & 1 & 2 & 1.04 \\
\hline $\begin{array}{l}\text { Guiding the learners' practice after giving them explicit instructions in } \\
\text { class }\end{array}$ & 8 & 10 & 3 & 4 & 4 & 2.52 & 1.41 \\
\hline Making use of various models, images, and objects during the lesson & 10 & 6 & 4 & 4 & 5 & 2.59 & 1.52 \\
\hline $\begin{array}{l}\text { Allowing students to discuss and explain mathematical concepts to } \\
\text { their colleagues to enhance a better understanding }\end{array}$ & 11 & 7 & 3 & 4 & 4 & 2.41 & 1.48 \\
\hline $\begin{array}{l}\text { Encouraging learners to practice using different methods and this also } \\
\text { requires the availability of different resources }\end{array}$ & 9 & 8 & 4 & 7 & 1 & 2.41 & 1.27 \\
\hline Sometimes using peer tutoring may assist in delivering the concepts & 8 & 15 & 4 & 2 & 0 & 2 & 0.85 \\
\hline Using the estimate-calculate-check routine & 5 & 10 & 0 & 6 & 8 & 3.07 & 1.56 \\
\hline $\begin{array}{l}\text { Always having mathematics symbols and terms displayed in the math } \\
\text { lesson }\end{array}$ & 16 & 7 & 1 & 3 & 2 & 1.9 & 1.29 \\
\hline $\begin{array}{l}\text { Allocation of more time in explaining the vocabularies such as minus, } \\
\text { less, subtract and take away etc. }\end{array}$ & 5 & 7 & 6 & 4 & 7 & 3.03 & 1.45 \\
\hline $\begin{array}{l}\text { Each stage of teaching should have a special time to practice and } \\
\text { consolidate different concepts, for instance, } 5 \text { minutes of practicing }\end{array}$ & 13 & 8 & 5 & 3 & 0 & 1.93 & 1.03 \\
\hline
\end{tabular}

Table 4.2 shows that, thirty four percent (34\%) strongly agreed that the use of relevant and familiar contexts should be linked to mathematics to assist learners with dyscalculia $(M=2.28, S D=1.22)$. Some of the practical ideas that can be implemented in the classroom include the league tables (such as in football), both inside and outside classroom resources (such as the playgrounds), real bank statements to help the students understand the financial mathematics, and car racings among others.

Chinn (2013) noted that, by linking relevant and familiar reallife contexts with mathematics, the dyscalculic learners will be able to appreciate mathematics as an applicable subject in life. Confining learners in a classroom set-up all along may contribute to the prevalence of dyscalculia.
About $45 \%$ agreed that allowing the students to move to the higher levels when they have understood the easier contexts would help in addressing some key issues associated with dyscalculia $(M=2, \mathrm{SD}=1.04)$.Teachers should, therefore, spend more time on the introductory stages before getting deeper into the topic. If possible, they should revisit the fundamental concepts severally. They can also demonstrate ideas using concrete materials and thereafter engage the learners in writing. Butterworth and Yeo (2004) noted that teachers should use concrete materials before introducing diagrams and pictures, which should then be introduced prior to putting down the abstract mathematical work.

Most (34\%) of the teachers agreed that it was important to guide the learners' practice after giving them explicit 
instructions in class $(M=2.52, \quad S D=1.41)$. Mathematics teachers should move about in the midst of learners as they oversee how various individuals, especially the weak learners, are undertaking a given task. Freeman et al (2014) noted that when teachers engage learners directly, those that grasp the concepts slowly will improve their performance on subjects such as mathematics and engineering. Teachers should, therefore, guide the students on the way to go about some tasks so that by the time they assign the students some homework, the students will be in a position to improve on the knowledge acquired in class.

Thirty-five per cent (35\%) of the teachers strongly agreed that making use of various models, images, and objects during the lesson would assist them in addressing some issues that are associated with dyscalculia $(M=2.59, S D=1.52)$. Real objects such as a globe will assist learners to understand the mathematical problems that involve latitudes and longitudes. They can be used repetitively whenever teachers want to revisit the foundation concepts of a mathematical problem. This works well when other strategies such as the ensuring that students move to the next level once they understand the simpler concepts. A multi-strategy approach helps to improve mathematics performance for dyscalculic learners (Williams, 2013).

About $38 \%$ strongly agreed that allowing students to discuss and explain mathematical concepts to their colleagues would enhance a better understanding and performance $(M=2.41$, $S D=1.48)$. Such sentiments are extensively supported in the literature (Hartman, 2001; Tobiason et al., 2014; Smith et al., 2009; and Sofroniou \& Poutos, 2016). It is clear that if mathematics teachers allow the good-performing learners to explain the concepts to their colleagues, it will break the culture where learners may think that they can only learn from their teachers. As such, mathematics teachers should also use the strategy to gauge the students' understanding over a particular problem. The strategy also allows the students to brainstorm in the presence of their teachers (Smith et al., 2009).

The highest percentage $(31 \%)$ of the teachers strongly agreed that encouraging learners to practice using different methods would assist the poorly performing learners to improve their performance $(M=2.41, S D=1.27)$. This would also require the availability of different resources. Teachers should guide learners in various ways of choosing different methods of tackling a particular mathematical problem. Teachers should always demonstrate how the different methods are used and encourage the learners to familiarize themselves with different strategies. According to Darling-Hammond\& BaratzSnowden (2005), an effective teacher should always demonstrate different problem solutions and encourage the students to familiarize themselves with all the methods learned. This may reduce some aspects of mathematics that causes anxiety among learners.
The majority on the issue was that (52\%) agreed that sometimes using peer tutoring may assist in delivering the concepts $(M=2, S D=0.85)$. Peer tutoring involves the use of students as mathematics tutors where good-performing students are paired with poor performers, which aids in appraising acute behavioral and academic concepts (Milleret al., 1996; Hott et al., 2012). Mathematics teachers in public day secondary schools in Kericho County should embrace the strategy because it helps to improve the performance of learners with dyscalculia (Heronet al., 1983). The tutoring may be in form of class-wide, cross-aged, one-to-one, small group instruction and home-based methods.

About $34 \%$, representing the majority of teachers, agreed that using the estimate-calculate-check routine was a good strategy to improve the performance of students with dyscalculia $(M=3.07, S D=1.56)$. The dyscalculic students should be guided on how to do estimations before doing the calculations. They should then calculate and after a fixed period of time, teachers should check (examine) whether the whole process has been concluded successfully. Regular reminders should be used to alert the students about being time conscious. The strategy can make use of peers to improve dyscalculic learners' performance (Hott et al., 2012). Teachers can capitalize on this strategy to have their students improve independence in thinking.

Fifty-five percent (55\%) strongly agreed that the mathematical performance of dyscalculic students would be improved by always having mathematics symbols and terms displayed in mathematics lessons $(M=1.9, S D=1.29)$. The strategy is critical especially to dyscalculic learners who confuse the symbols, signs, and terms. Tambychik\& Meerah (2010) explained that this was in connection with the mental disorder. Therefore, teachers should always endeavor to present the relevant mathematical symbols and vocabularies in each lesson. This may reduce the need to allocate more time in explaining the vocabularies such as minus, less, subtract, and take away among others as shown in the responses presented in Table 4.2.

As such, while $24 \%$ agreed that the allocation of more time in explaining the vocabularies was a good teaching strategy, $24 \%$ strongly disagreed with the researcher's suggestion.

This confirms that displaying mathematics symbols and terms in all mathematics classes is a right move to assist in the improvement of dyscalculic students' performance.

Forty five percent (45\%) strongly agreed that each stage of teaching should have a special time to practice and consolidate different concepts, for instance, five minutes should be allocated for practicing the learned concepts ( $M=1.93, S D=1.03)$. According to Mwangi(2013), enough time should be allocated to teaching students with special needs. As such, teachers should spare some of their time to concentrate on dyscalculic students at each stage of learning a particular topic to enhance their mathematics performance. 


\section{V.CONCLUSIONSAND RECOMMENDATIONS}

The strategies used to teach mathematics in Kericho County incorporate lectures, problem solving, deductive, analytical, and inductive methods. These strategies are quite fitting but fall short of meeting the learning requirements posed by students suffering from dyscalculia.

The study summed up that there was little effort from parents' side to assist learners to improve their performance because they expected teachers to assist the students fully. That was a challenge that mathematics teachers experienced, which was aggravated by poor cooperation from other stakeholders. Also, some of the dyscalculia issues might not have been resolved due to lack of enough teachers who had trained in special needs education.

Failure to improve the mathematics performance might have been caused by non-use of ICT in teaching learners with dyscalculia. Computer-based programs might help such learners to grasp some concepts. Students with dyscalculia as well as those who were struggling with mathematics might have suffered academic failure due to lack of learning spaces with minimal distraction. Also, students were not allowed to verbalize their thinking, which was a drawback to good performance. Shockingly, there were few mathematics teachers who did not believe in the effectiveness of group discussions in class as well as use of homework to improve learners' performance. This might have lowered students' chances of learning from their colleagues.

Also, not all teachers believed in allocation of special time for students with learning disabilities. Poorly performing learners would have improved their performance if all the teachers linked abstract mathematics to real-life familiar contexts such as playgrounds.

Based on the findings of the study, the following were recommended

Teachers should tailor the existing strategies to better address the 6.3\% dyscalculic students and also adequately accommodate the $93.7 \%$ of the students who are merely struggling with mathematics also teachers should reach out for the parents to convince them that dyscalculic learners need help from inside and outside the learning institutional set-ups.

The Ministry of Education should spearhead efforts to design inclusive curriculums which cater for the specialized learning needs of dyscalculic learner, it should also offer Teachers with training on the complexities of dyslexia as well as be teach them eventful methods of simplifying the impacts that dyscalculia introduces in the classroom.

\section{CONTRIBUTION TO KNOWLEDGE}

The study is of benefits in terms of eradicating the stigma associated with poor performance in mathematical courses. Hence, the study is an essential pillar on which appropriate corrective and restorative measures can be implemented in lower secondary classes as well as during the formative and progressive stages of students in primary schools. This may, in turn, alleviate the high levels of mathematical illiteracy in the focus county and the country at large. Also, the results will assist other scholars in related disciplines to carry out their own studies.

\section{ACKNOWLEDGEMENTS}

I humbly acknowledge God the father for granting me the gift of grace and ability to concentrate in my studies, for his divine wisdom that he gave me to carry on throughout this study. I am duly and deeply indebted to my supervisors for their positive criticism and dedicating their time and attention to enable me come up with this splendid piece of work. I deeply acknowledge the management of Kericho County Commisioner Office and Kericho County Director of Education Office for participating in the study and finally Kenyatta Universityfor their support and service they have contributed towards my studies in the institution.

\section{CONFLICT OF INTEREST}

I. on behalf of all the co-authors declare that author(s)have no conflict of interest with the manuscript

\section{REFERENCES}

[1] Carnine, D., Jitendra, A., \& Silbert, J. (1997). A descriptive analysis of mathematics curricular materials from a pedagogical perspective. Remedial and Special Education, 18, 66-81.

[2] Carr, N. S. (2013). Increasing the effectiveness of homework for all learners in the inclusive

[3] Eison, J. (2010). Using active learning instructional strategies to create excitement and enhance learning. Jurnal Pendidikantentang Strategi Pembelajaran Aktif (Active Learning) Books, 2(1), 1-10.

[4] Furlong, M., McLoughlin, F., McGilloway, S., \& Geary, D. (2016). Interventions to improve mathematical performance for children with mathematical learning difficulties (MLD). Cochrane Database of Systematic Reviews 2016, Issue 4. Art. No.: CD012130.

[5] Gafoor, K. A., \& Kurukkan. A. (2015). Learner and teacher perception on difficulties in learning

[6] Hannel, G. (2013). Dyscalculia: Action plans for successful learning in Mathematics. New York: Routledge.

[7] Kenney, J., Hancewicz, E., Heuer, L., Metsisto, D., \& Tuttle, C. (2005). Literacy Strategies for Improving Mathematics Instruction. Alexandria: Association for Supervision and Curriculum Development.

[8] Kiplagat, P., Role, E., \& Makewa, L. N. (2012). Teacher commitment and mathematics performance in primary schools: A meeting point!. International Journal of Development and Sustainability, 1(2), 286-304.

[9] Lovell, E. (2002). Mathematical discussion in the classroom. Philosophy of Mathematics Education Journal, 16.

[10] Miller, A. D., Barbetta, P. M., Drevno, G. E., Martz, S. A., \& Heron, T. E. (1996). Math peer tutoring for students with specific learning disabilities. Learning Disability Forum, 21(3), 21-28.

[11] Mutambuki, E. K. (2014). The effect of SMASSE project on performance of mathematics in secondary schools in Kitui Central District, Kitui County, Kenya. Unpublished masters' thesis. South Eastern Kenya University, Kitui.

[12] Nyaga, S. N. (2012). Influence of Learning Support Strategies on Academic Performance of Learners with Dyscalculia: A Case of Selected British National Curriculum Based Preparatory Schools in the Nairobi County, Kenya. Unpublished doctoral thesis. University of Nairobi.

[13] Orodho, J. A., Waweru, P. N., Ndichu, M., \& Nthinguri, R. (2013). Basic education in Kenya: Focus on strategies applied to 
cope with school-based challenges inhibiting effective implementation of curriculum. International Journal of Education and Research, 1(11), 1-20.

[14] Soares, N., Evans, T., \& Patel, D. (2018). Specific learning disability in mathematics: a comprehensive review. Translational Pediatrics, 7(1), 48-62.

[15] Sofroniou, A., \& Poutos, K. (2016). Investigating the effectiveness of group work in mathematics. Education Sciences, 6(3), 30.

[16] Taiwo, C (1972). Mathematics Teaching in schools. London: Commonwealth Secretariat

[17] Tuchura, D. G. (2016). Analysis of teachers' remedial strategies for enhancing mathematics skills to learners with dyscalculia in regular primary schools in Nyandarua County, Kenya.Masters of Education Thesis, Kenyatta University.

[18] Waititu, M. M., \& Orado, G. N. (2009). Managing teachers and the instruction of mathematics and science: Lessons from the SMASSE experience in capacity development. In Secondary Education in Africa (SEIA) Follow-up Technical Workshop on Science and Mathematics.

[19] World Bank. (2004). Strengthening the foundation of education and training in Kenya. Opportunities and Challenges in Primary and General Secondary Education. Report No. 28064-KE. 